ISSN 1112-9867

Available online at

http://www.jfas.info

\title{
LIQUID-LIQUID EXTRACTION OF IRON (III) FROM OUENZA IRON ORE LEACH LIQUOR BY TRIBUTYLPHOSPHATE
}

\author{
A. Nouioua*, D. Barkat \\ Laboratory of chemical molecular and environment, Department of Industrial Chemistry, \\ Faculty of Science and Technology, Biskra University, 07000 Biskra, Algeria
}

Received: 01 May 2017 / Accepted: 25 August 2017 / Published online: 01 September 2017

\begin{abstract}
The solvent extraction of iron (III) from the hydrochloric acid leach liquor of iron ore from mine of Ouenza, Algeria with tributylphosphate (TBP) in chloroform was studied. The effect of several parameters, such as contact time, $\mathrm{HCl}$ concentration, TBP concentration and chloride inorganic salt $(\mathrm{KCl})$ concentration on the efficiency of extraction of iron was examined at $19 \pm 2$ ${ }^{\circ} \mathrm{C}$. It was found that, for $2 \mathrm{~min} 3 \mathrm{M}$ TBP in presence of $5 \mathrm{M} \mathrm{HCl}$ and $2 \mathrm{M} \mathrm{KCl}$ solutions led to a high yiel of extraction (98.57\%) of iron (III).

The stoichiometry of the extracted species was determined by using the method of slope analysis. The number of moles of $\mathrm{H}^{+}, \mathrm{Cl}^{-}$and TBP associated with the extracted species was determined and the extracted species was found to be $\mathrm{HFeCl}_{4}(\mathrm{TBP})_{2}$.
\end{abstract}

Keywords: solvent extraction; iron (III); Tributylphosphate; leach liquor; Mine Ouenza.

Author Correspondence, e-mail: toschini@yahoo.fr

doi: http://dx.doi.org/10.4314/jfas.v9i3.14

\section{INTRODUCTION}

Mineral leaching is an applied method for recovering precious metals from ores [1]. The use of hydrochloric acid for the dissolution of an iron ore generally results in a solution with a high concentration of ferric iron [2]. 
The iron of the leach solution is important in hydrometallurgy. Removal or recovery of iron from a chloride-rich solution may be carried out by precipitation or by solvent extraction techniques [3].

Liquid-liquid extraction is one of the most widely used industrial separation processes, allowing the separation, purification and concentration of various metal ions. This method extensively applied by the recovery of appreciable quantities of metallic elements either for the protection of the environment or their recovery for use in the industrial sector [1].

In the extraction of metal ions, the choice of the extractant molecule is a key element of the extraction process [4]. Indeed, it must have a high extracting power and be optionally selective with respect to the targeted metal solute.

Many researchers have carried out solvation extraction to study the recovery of iron (III), where the extractants possess donor atoms $(\mathrm{O}, \mathrm{N}, \mathrm{S}, \mathrm{P})$ without labile hydrogen via these groups, the extractant may partially or totally substitute for the hydration molecules of the cation, and solvate the metal. In the case of an extractant $\mathrm{E}$, a metal cation $\mathrm{M}^{\mathrm{m+}}$ and anion $\mathrm{X}^{-}$, the extraction is described by the following equilibrium:

$$
M^{m+}+X^{-}+E_{\text {org }} \rightleftharpoons M X_{m} E_{\text {org }}
$$

The experimental use of this relation makes it possible to determine the stoichiometric coefficients of the equilibrium, by varying a single parameter. Extraction will be all the stronger as the extractant concentration $\mathrm{E}$ is high. Similarly, charging the aqueous phase with $\mathrm{X}^{-}$ions, in the form of acid or non-extractable salt, favors extraction [5].

It is very difficult to separate iron (III) from aqueous solutions after hydrometallurgical processes of recovering a number of non-ferrous metal ions [6]. In the separation of iron (III) from aqueous chloride, various publications have dealt with the application of organophosphorus acids and derivatives of organophosphorus compounds. Ferric iron has a strong tendency to form complexes with the chloride ion which can be selectively extracted by TBP [7-11].

Tributylphosphate (TBP) is an organophosphate compound $\left(\mathrm{C}_{12} \mathrm{H}_{27} \mathrm{O}_{4} \mathrm{P}\right)$ characterized by low solubility in water, exceptional chemical resistance, high polarity and very low vapor pressure [12-14]. 
The presence of the phosphate functional group allowing specific ligand properties and the overall physicochemical properties make TBP an excellent industrial solvent widely used as an extractant and complexing agent [12].

In this work, the influence of the chloride concentration, the aqueous acid concentration and the concentration of extractant on the efficiency of extraction of iron (III) from the hydrochloric acid leach liquor of iron ore from mine of Ouenza, Algeria with TBP in chloroform was studied.

\section{RESULTS AND DISCUSSION}

\subsection{Analysis of the leaching of iron ore with hydrochloric acid}

The chemical analysis of the iron ore from Ouenza, Algeria by using X-ray fluorescence spectrometry (XRF) gave the following results: $\mathrm{SiO}_{2}, 1.29 ; \mathrm{Al}_{2} \mathrm{O}_{3}, 0.17 ; \mathrm{Fe}_{2} \mathrm{O}_{3}, 76.19 ; \mathrm{CaO}$, $10.18 ; \mathrm{MgO}, 3.86 ; \mathrm{K}_{2} \mathrm{O}, 0.05 ; \mathrm{SO}_{3}, 0.03(\%)$. The leaching process was applied to the iron ore rock to recover the iron element. Various parameters such as concentration of hydrochloric acid $(0.5-12 \mathrm{~mol} / 1)$, leaching temperature $\left(30-80^{\circ} \mathrm{C}\right)$, agitation rate $(90-450 \mathrm{rpm})$ and $(0.063-0.5 \mathrm{~mm})$ under different conditions to study their influence on leaching efficiency, and determine the best conditions that give a very high rate of dissolution of iron in hydrochloric acid. Using a particle size of $0.063 \mathrm{~mm}$ in $12 \mathrm{~mol} / \mathrm{l} \mathrm{HCl}$ and a solid / liquid ration 1: 100 at $80{ }^{\circ} \mathrm{C}$, in 2 hours with a stirring speed $=360 \mathrm{rpm}$, about $97.6 \%$ of the iron total in the rock was dissolved in the hydrochloric acid solution (Fig .1), this ratio represents an estimated iron (III) concentration of $0.093 \mathrm{M}$ [15].

For an iron ore of hematite type, the reaction of the dissolution of the iron is written as follows [2]:

$$
\mathrm{Fe}_{2} \mathrm{O}_{3}+6 \mathrm{HCl} \rightleftharpoons 2 \mathrm{FeCl}_{3}+3 \mathrm{H}_{2} \mathrm{O}
$$

The solution chosen for extraction by TBP contains about $0.01329 \mathrm{M}$ of iron (III), this concentration was obtained during the leaching of the ore of particle size $0.063 \mathrm{~mm}$ in 0.5 $\mathrm{mol} / \mathrm{l} \mathrm{HCl}$ and a solid / liquid ration $1: 100$ at $80{ }^{\circ} \mathrm{C}$, in 1 hour with a stirring speed $=360$ rpm. 


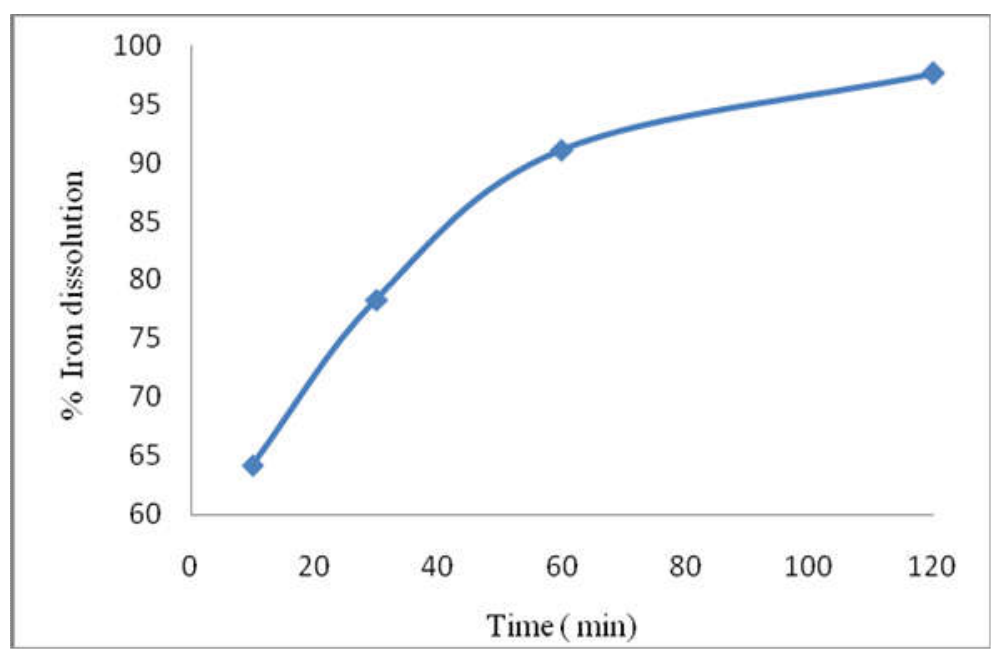

Fig.1.Effect of $\mathrm{HCl}$ concentration on iron ore dissolution [15]

\subsection{Analysis of the extraction of iron (III) with TBP dissolved in chloroform}

\subsubsection{Effect of contact time on the extraction of iron (III)}

The iron (III) extraction was studied with different contact times to determine the equilibrium reaction time for subsequent experiments under the following conditions : $[\mathrm{Fe}]=0.01329 \mathrm{M}$, $[\mathrm{TBP}]=1 \mathrm{M},[\mathrm{HCl}]=5 \mathrm{M},[\mathrm{KCl}]=2 \mathrm{M}$, ratio $(\mathrm{O} / \mathrm{A}) 1: 1$, stirring rate $300 \mathrm{rpm}$ and reaction temperature of $19 \pm 2^{\circ} \mathrm{C}$. The results are presented in Fig.2.

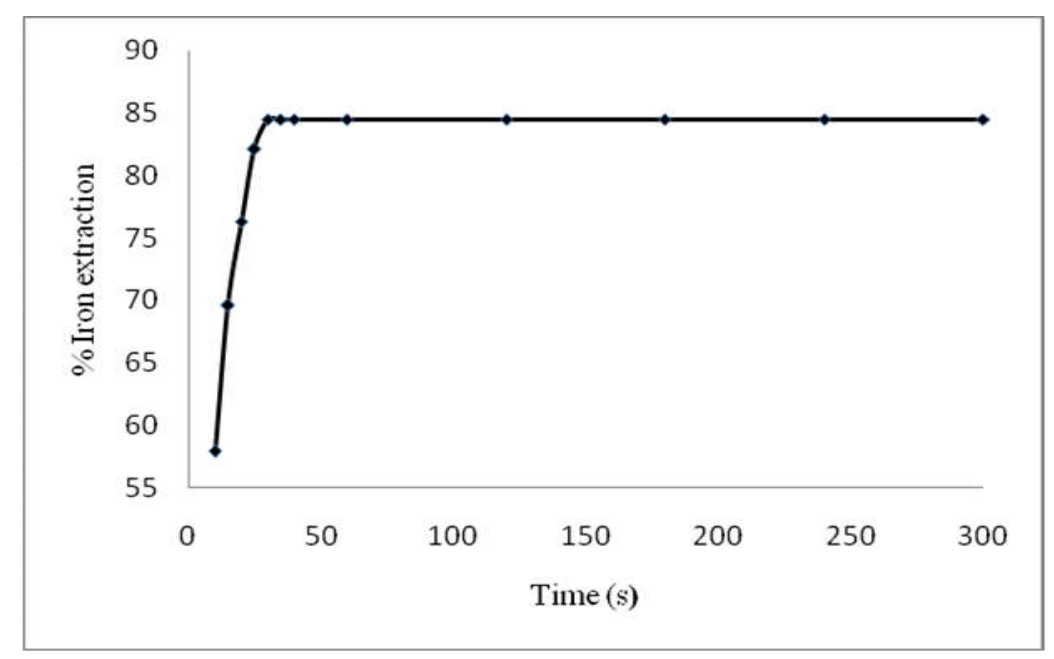

Fig.2. Effect of contact time on iron extraction

Fig.2. shows that as the contact time increased from $10 \mathrm{~s}$ to $30 \mathrm{~s}$ the percentage of iron extraction increases rapidly from 57.9 to $84.45 \%$. After 30 s min the extraction remains 
constant until $5 \mathrm{~min}$. So the extraction in these conditions was reached within only $2 \mathrm{~min}$ and it was chosen as the reaction time for all the following experiments.

\subsubsection{Effect of $\mathrm{HCl}$ concentration}

The hydrochloric acid concentration in feed liquor has an important influence on iron extraction [16]. It has been reported that $\mathrm{FeCl}_{3}$ in the presence of $\mathrm{HCl}$ contributes to form $\mathrm{HFeCl}_{4}$ which could then combine with TBP in the extracted complex and facilitates extraction reaction [9].

The effect of $\mathrm{HCl}$ concentration in the range of 1 to $9 \mathrm{M}$ has been investigated using a constant $\mathrm{KCl}$ concentration of $2 \mathrm{M}$ on iron (III) extraction. The extractions were carried out with a TBP of fixed concentration equal to $0.5 \mathrm{~mol} / 1$ in chloroform at a temperature of $19 \pm$ $2{ }^{\circ} \mathrm{C}$ and the results are given in Fig.3.

It is clear from the figure that the iron (III) extraction percentage increases with increasing $\mathrm{HCl}$ concentration. Therefore, $[\mathrm{HCl}]=9 \mathrm{~mol} / \mathrm{l}$ was noted as the optimum concentration for iron (III) extraction, where approximately $86.08 \%$ extraction efficiency was achieved.

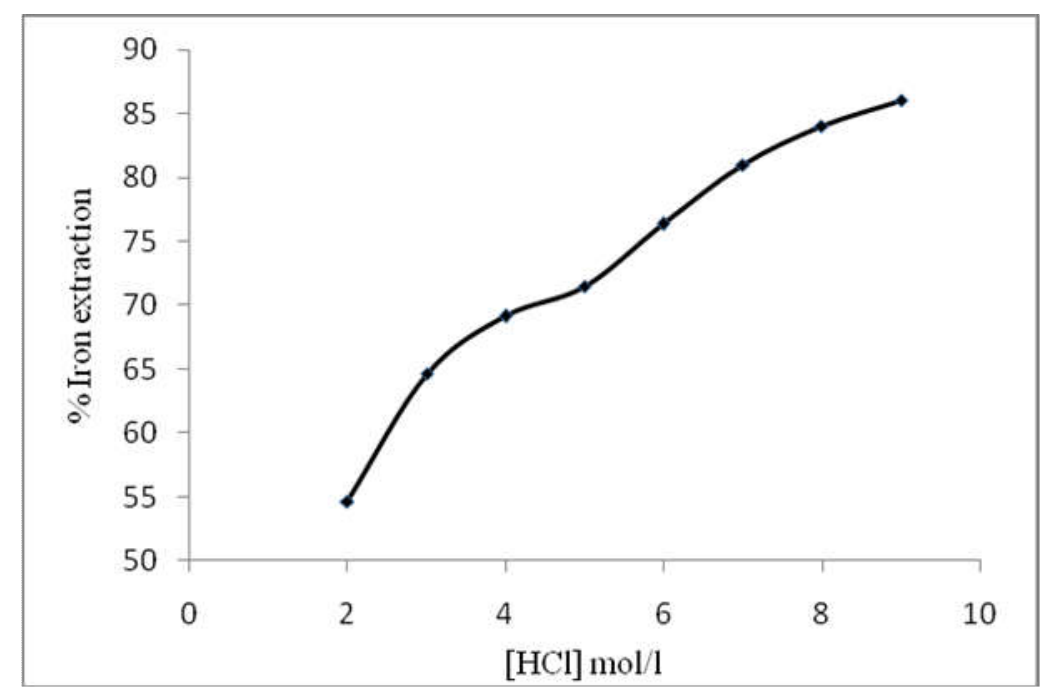

Fig.3. Effect of $\mathrm{HCl}$ concentration on extraction of iron (III)

The plot of $\log \mathrm{D}$ versus $\log \left[\mathrm{H}^{+}\right]$Fig.4 has a slope of 1.08 supports the presence of one hydrogen ion in the extracted iron complex. 


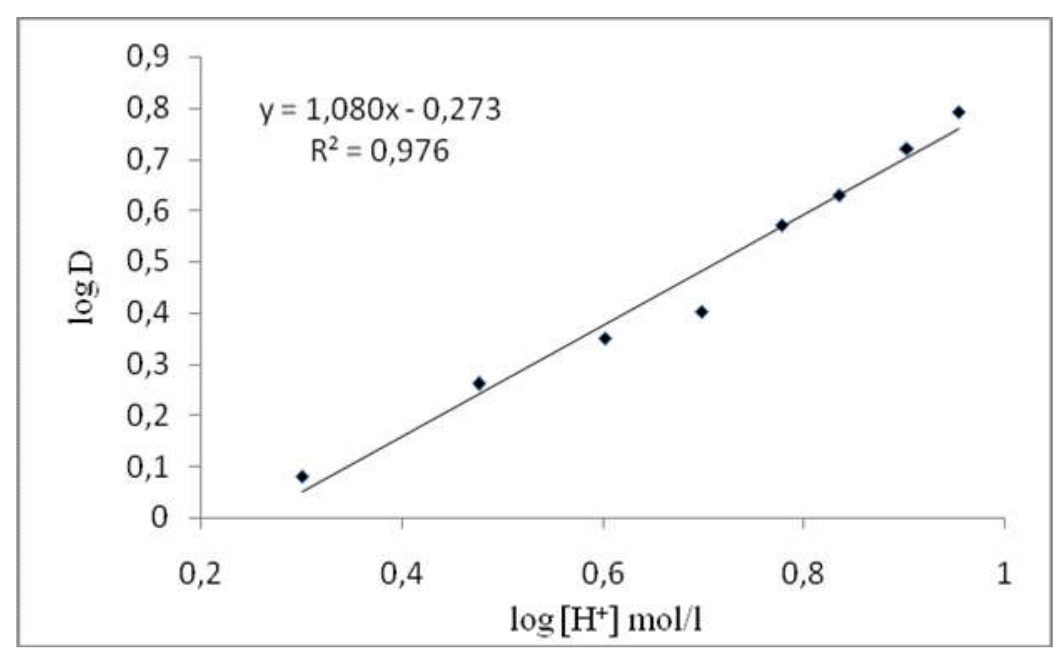

Fig.4. Plot of $\log \mathrm{D}$ versus $\log \left[\mathrm{H}^{+}\right] \mathrm{mol} / \mathrm{l}$ for the extraction of iron (III)

\subsubsection{Effect of $\mathrm{KCl}$ concentration}

The effect of chloride ions on the extraction of iron (III) by $0.5 \mathrm{~mol} / 1$ of TBP in chloroform from leach liquor containing $5 \mathrm{~mol} / 1$ of hydrochloric acid was investigated. The chloride concentration was varied by adding different amounts of $[\mathrm{KCl}]$. The results are presented in Fig.5.

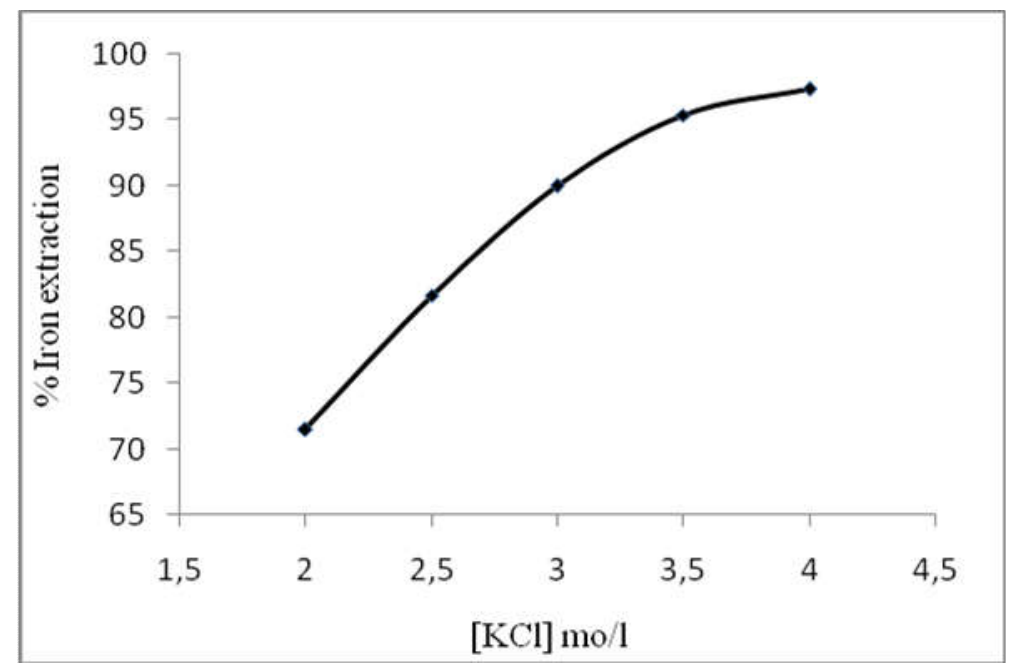

Fig.5.Effect of $\mathrm{KCl}$ concentration on extraction of iron (III)

As seen, the figure illustrates an increase in iron extraction from 71.48 to $97.29 \%$ with an increase in chloride concentration. This shows the association of chloride ions in the extracted iron complex. 
The linear plot of $\log \mathrm{D}$ vs $\log \left[\mathrm{Cl}^{-}\right]$in Fig. 6 with slop value of 3.9 indicating the involvement of four chloride ions in the extracted complex of iron (III).

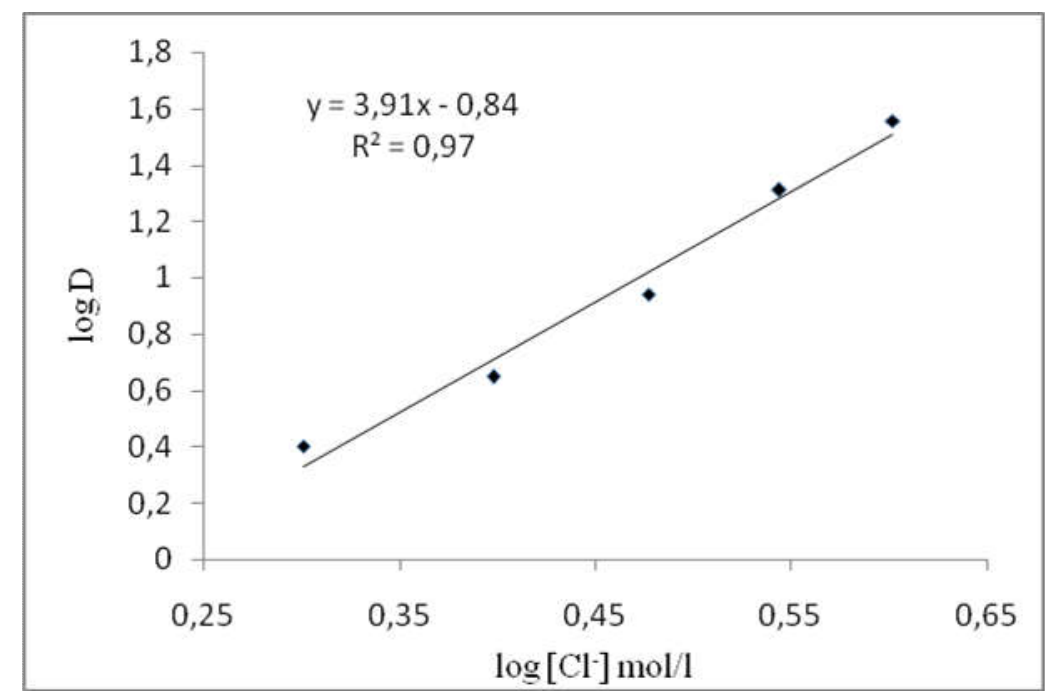

Fig.6.Plot of $\log \mathrm{D}$ versus $\log \left[\mathrm{Cl}^{-}\right] \mathrm{mol} / \mathrm{l}$ for the extraction of iron (III)

\subsubsection{Effect of TBP concentration}

The effect of TBP concentration within $(1-3 \mathrm{M})$ on the extraction of iron (III) from the aqueous solution bearing $2 \mathrm{M} \mathrm{KCl}$ and $5 \mathrm{M} \mathrm{HCl}$ was studied. The experimental results plotted in Fig.7, shown that the percentage of iron (III) extracted increase rapidly from 84.45 to $98.57 \%$ with increasing TBP concentration.

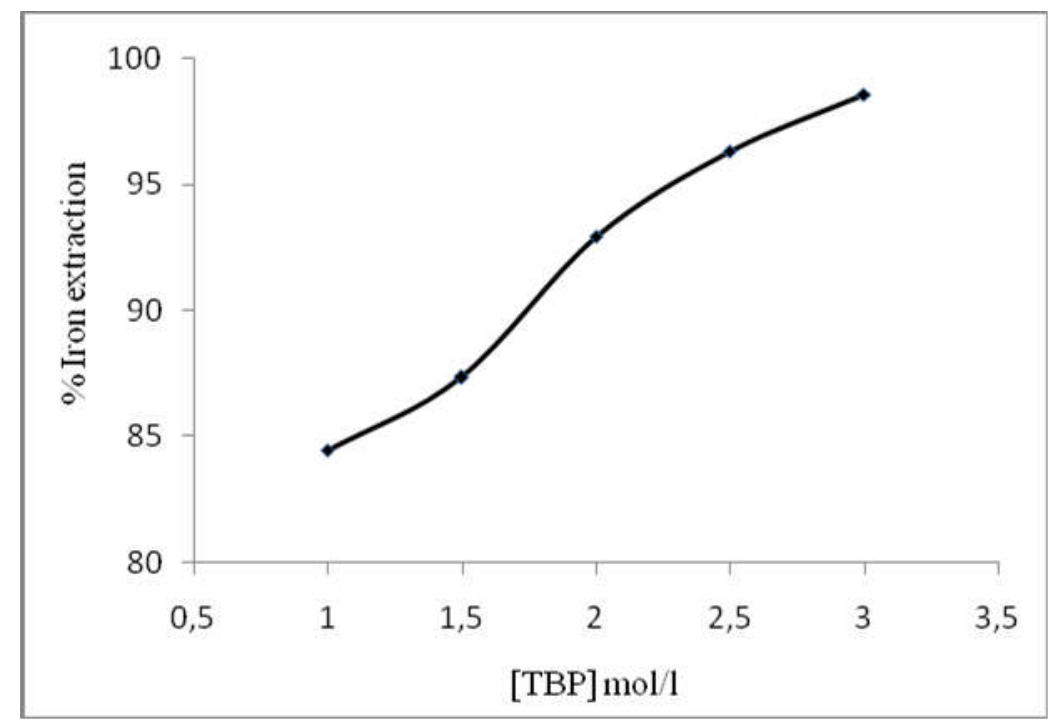

Fig.7.Effect of TBP concentration on extraction of iron (III) 
The plot of $\log$ D vs $\log$ [TBP] for extraction of iron (III) as presented in Fig.8, illustrates the slope of 2.2 which indicates that two molecules of TBP participate in the extraction of iron (III).

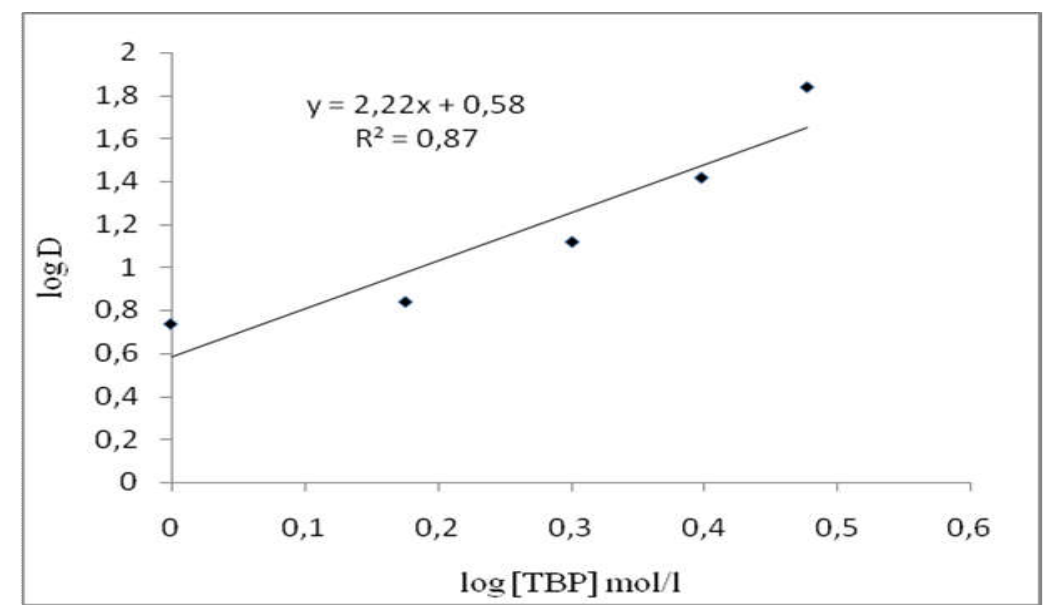

Fig.8.Plot of $\log$ D versus $\log [\mathrm{TBP}] \mathrm{mol} / \mathrm{l}$ for the extraction of iron (III)

Therefore, based on the slope analysis of the obtained experimental data, the most probable composition of the extractable species can be represented by:

$$
\mathrm{FeCl}_{4}^{-} a q+\mathrm{H}_{a q}^{+}+2 \mathrm{TBP}_{\mathrm{org}} \rightleftharpoons \mathrm{HFeCl}_{4}(\mathrm{TBP})_{2 \mathrm{org}}
$$

This is in agreement with the previously reported data for the extraction of iron (III) from hydrochloric acid solutions with TBP [17-18].

\subsection{UV and IR spectral studies}

The yellowish brown color of the aqueous solution indicat the presence of tetrahedral species $\mathrm{FeCl}_{4}^{-}$and octahedral species $\left[\mathrm{FeCl}_{4}\left(\mathrm{H}_{2} \mathrm{O}\right)_{2}\right]^{-}$because of charge transfer band in the ultraviolet spectra in which tails coming into the visible [19]. The aqueous and organic phases were examined by the UV-Visible spectra. From the spectra of leach liquor of iron ore in hydrochloric acid in the presence of $\mathrm{KCl}$ Fig.9, the characteristic bands at around 230, 290, 350 $\mathrm{nm}$ are due to the formation of $\mathrm{FeCl}_{4}^{-}[20]$. When compared the spectrum of the organic phase with that of the aqueous phase, it can be seen that the absorptions are in the same frequencies of spectrum of the aqueous solution, containing the stoichiometric composition of $\mathrm{HFeCl}_{4}(\mathrm{TBP})_{2}$ according to the equilibrium equation (2). 


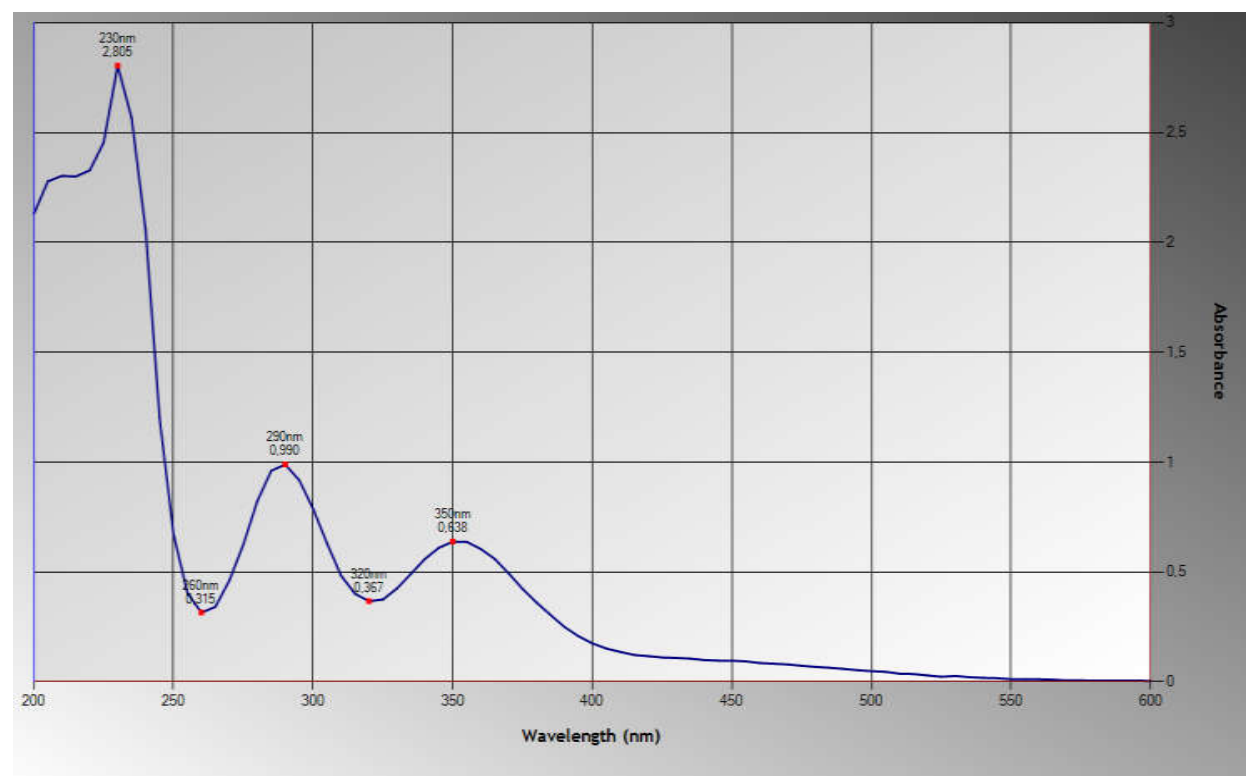

Fig.9.UV-Vis spectrum of iron complex with tributylphosphate

The functional group $\mathrm{P}=\mathrm{O}$ is the only part of TBP which is able to exert the solvent electron donor [20]. To confirm this, the organic extract with TBP in chloroform from the hydrochloric acid leach liquor of iron ore aqueous solution was examined by IR spectroscopy. The spectra of TBP alone and TBP-Iron (III) are shown in Figure.10.

From Figure.10, it can be seen that the band associated with the vibration of the $\mathrm{P}=\mathrm{O}$ bond (around $1273.9 \mathrm{~cm}^{-1}$ ) [21], in the presence of iron, shifts towards the high frequencies of $\left(1280.65 \mathrm{~cm}^{-1}\right)$, these changing indicate the possibility of bonding between iron and TBP.

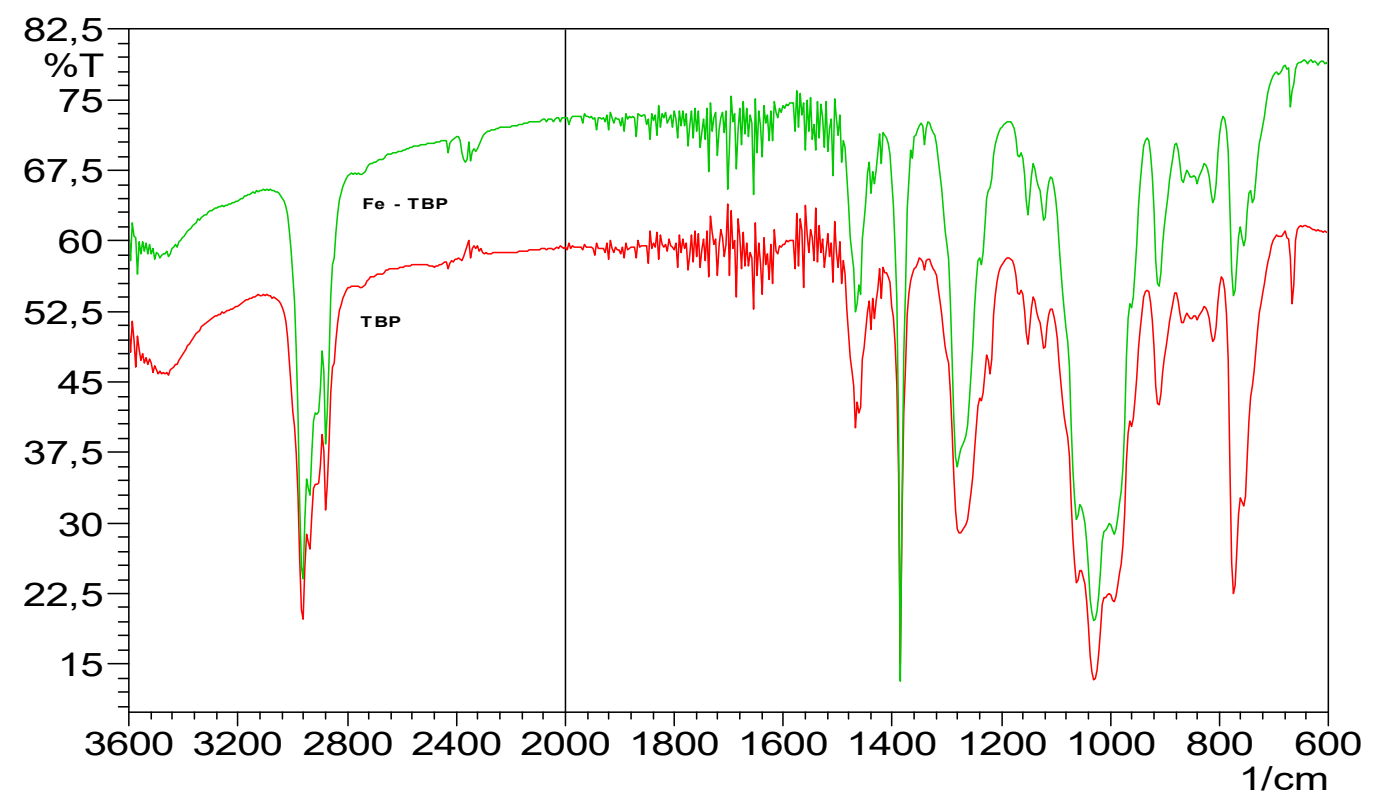

Fig.10.IR spectra of extractant and iron loaded organic phase 


\section{EXPERIMENTAL}

\subsection{Reagents and solutions}

- The commercial extractant TBP (tributyphosphate) $\left(\mathrm{C}_{12} \mathrm{H}_{27} \mathrm{O}_{4} \mathrm{P}\right) 97 \%$ without further purification.

- Organic diluents chloroform was pre-equilibrated with aqueous solution of $\mathrm{NaCl}$ and distilled water.

- The leachate liquor contained 0.01329 M of iron III.

- Potassium chloride.

- Hydrochloric acid.

- Potassium thiocyante solution (KSCN).

\subsection{Extraction Procedures}

The experiments were carried out by shaking equal volumes $(10 \mathrm{ml})$ of aqueous phase; mixture of leach liquor, hydrochloric acid and potassium chloride and organic phase containing ( 0.5 to $3 \mathrm{M}$ TBP) diluted in chloroform, the mixture was mechanically stirred (300 rpm) for $2 \mathrm{~min}$ at a temperature of $19 \pm 2{ }^{\circ} \mathrm{C}$. Once the mixing phases were separated, the iron (III) concentration in the aqueous phase was determined by spectrophotometric and thiocyanate method and measured the absorbance at $465 \mathrm{~nm}$ using a UV-Visible spectrophotometer JENWAY-7315. The concentration of Fe (III) in the organic phase was calculated from the mass balance. The percentage extraction ( $\%$ E) was calculated by the following equation [22]:

$$
\% E=\frac{D}{D+1} 100
$$

The equilibrium slope method $\left(\log \mathrm{D}\right.$ vs $\log \left[\mathrm{H}^{+}\right], \log \left[\mathrm{Cl}^{-}\right]$and $\left.\log [\mathrm{TBP}]\right)$ has been used to analyze the experimental data for each extraction system. The distribution ratio (D) was determined as follows [22]:

$$
D=\frac{[\mathrm{Fe}]_{\text {org }}}{[\mathrm{Fe}]_{a q}}
$$

\section{CONCLUSION}

Using $0.063 \mathrm{~mm}$ particle size in $12 \mathrm{M} \mathrm{HCl}$ with solid/ liquid ration 1:100 within 2 hours and at $80^{\circ} \mathrm{C}$, about $97.6 \%$ of iron (III) was passed from Ouenza iron ore into solution. 
The results of fundamental studies on the solvent extraction of iron (III) from hydrochloric acid leach liquor contains about $0.01329 \mathrm{M}$ of iron (III) by TBP in chloroform showed that the extraction of metal ions increased with increasing $\mathrm{HCl}, \mathrm{KCl}$, TBP concentrations. The composition of the extractable species is found to be $\mathrm{HFeCl}_{4}(\mathrm{TBP})_{2}$ With $5 \mathrm{M} \mathrm{HCl}, 2 \mathrm{M} \mathrm{KCl}$ and $3 \mathrm{M}$ TBP at $19 \pm 2{ }^{\circ} \mathrm{C}$ about $98.57 \%$ of iron (III) was extracted.

\section{REFERENCES}

[1] El Bar D, Barket D. Journal of Mining Science, 2015, Vol. 51, No. 1, 179-185, doi: 10.1134/S106273911501024X.

[2] Alafara A B, Adekola F A, Folashade A O. Quantitative leaching of a Nigerian iron ore in hydrochloric acid. J. Appl. Sci. Environ. Mgt., 2005, Vol. 9, N. 3, 15-20.

[3] Mishra R K, Rout P C, Sarangi K, Nathsarma K C. J. Hydrometallurgy, June 2011, 108(1), 93-99, doi: 10.1016/j.hydromet.2011.03.003

[4] Belkhouche N E, M. Didi A, Villemin D. Solvent Extraction and Ion exchange, 2005, 23(5), 677-693, doi: 10.1081/SEI-200066290

[5] Iadaden S. Microfluidic extraction of divalent metal cations by affinity membranes, University Mouloud Mammeri of Tizi-Ouzou, 2010, pp.8.

[6] Pospiech B, Walkowiak W. Studies on iron(III) removal from chloride aqueous solutions by solvent extraction and transport through polymer inclusion membranes with D2EHPA, J. Physicochem. Probl. Miner. Process, 2010, 44, 195-204.

[7] Lupi C, Pilone D. Reductive stripping in vacuum of Fe(III) from D2EHPA, J.Hydrometallurgy, 2000, 57(3), 201-207.

[8] Jayachandran J, Dhake P M. Liquid-liquid extraction separation of iron(III) with 2- ethyl hexyl phosphonic acid mono 2 - ethyl hexyl ester. Talanta, 1997 Jul, 44 (7), 1285-1290.

[9] Saji J, Reddy M L P. Hydrometallurgy, 2001. 61 (2), 81-87, doi: 10.1016/S0304-386X(01)00146-3

[10] Saji J, Prasada RT, Iyer C S P and Reddy M L P. Extraction of iron(III) from acidic chloride solutions by Cyanex 923. Hydrometallurgy, 1998, 49, 289-296.

[11] Gupta B, Deep A, Singh V and Tandon S N. Recovery of cobalt, nickel, and copper from sea nodules by their extraction with alkylphosphines. Hydrometallurgy, 2003, 70, 121-129. 
[12] Renato C, Mark P J, Paul G R, Zdenek K, Marian B and Pappanan T. Langmuir, 2004, 20 (25), 10798-10808, doi: 10.1021/la0488957

[13] Reddy B R, Bhaskara Sarma P V R. Extraction of iron (III) at macro-level concentrations using TBP, MIBK and their mixtures, Hydrometallurgy, 1996, 43, 299-306.

[14] Zou L, Chen J, Pan X. Hydrometallurgy, 1998, 50, 193-203, doi: 10.1016/S0304-386X (98) 00017-6

[15] Nouioua A, Barkat D. Set for publication in Journal of Mining Science,2016.

[16] Lee M S, Lee K J and $\mathrm{Oh} \mathrm{Y} \mathrm{J.} \mathrm{Solvent} \mathrm{extraction} \mathrm{equilibria} \mathrm{of} \mathrm{FeCl}_{3}$ from hydrochloric acid solution with Alamine336, Materials Transactions, 2004, 45 (7), 2364-2368.

[17] Man-Seung L, Gwang-Seop L and Keun Y S. Solvent extraction equilibria of $\mathrm{FeCl}_{3}$ with TBP. Materials Transactions, 2004, 45 (6), pp. 1859 to 1863.

[18] El Dessouky S I, El-Nadi Y A, Ahmed I M, Saad E A and Daoud J A. Solvent extraction separation of $\mathrm{Zn}(\mathrm{II}), \mathrm{Fe}(\mathrm{II}), \mathrm{Fe}(\mathrm{III})$ and $\mathrm{Cd}(\mathrm{II})$ using tributylphosphate and CYANEX 921 in kerosene from chloride medium Chemical Engineering and Processing: Process Intensification, February 2008, 47 (2), 177-183.

[19] Sato T. Liquid-liquid Extraction of Iron (III) from Hydrochloric Acid Solutions by Tributyl Phosphate, J. Shigen-to-Sozai, 2002, 118 (9), 612-616.

[20] Pietro C, Tilde de C, Daniela C, Domenico L, Lorena T and Vincenzo T L. Colloid and Polymer Science, February 2015, 293(2), 597-603, doi: 10.1007/s00396-014-3439-x

[21] Zhanga G, Chena D, Weia G, Zhaoa H, Wanga L, Qia T, Menga F and L. Menga, Extraction of iron (III) from chloride leaching liquor with high acidity using tri-n-butyl phosphate and synergistic extraction combined with methyl isobutyl ketone, J. Separation and Purification Technology, 2015, 150, 132-138.

[22] Beata P, Wladyslaw W and Micha J W. Applicationtof TBP in selective removal of iron (III) in solvent extraction and transport through polymer inclusion membranes processes, Physicochemical Problems of Mineral Processing, 2005, 39, 89-98.

\section{How to cite this article:}

Nouioua A and Barkat D. Liquid-liquid extraction of iron (III) from Ouenza iron ore leach liquor by tributylphosphate. J. Fundam. Appl. Sci., 2017, 9(3), 1473-1484. 